\title{
Note on translations
}

Unless otherwise stated, all English translations of Spanish texts are the author's. 
Blank page

Christina H. Lee - 9781784996970 Downloaded from manchesterhive.com at 04/26/2023 03:37: ๑6PM via free access 